\title{
Original
}

\section{Characteristics of sleep-disordered breathing in J apanese patients with acromegaly}

\author{
Susumu Kashine ${ }^{1)}$, Ken Kishida ${ }^{1), 2)}$, Tohru Funahashi ${ }^{1), 2)}$ and Iichiro Shimomura ${ }^{1)}$ \\ ${ }^{1)}$ Department of Metabolic Medicine, Graduate School of Medicine, Osaka University, Suita 565-0871, Japan \\ ${ }^{2)}$ Department of Metabolism and Atherosclerosis, Graduate School of Medicine, Osaka University, Suita 565-0871, Japan
}

\begin{abstract}
Sleep-disordered breathing (SDB), especially sleep apnea-hypopnea syndrome (SAS), is often observed in patients with active acromegaly. This complication is a risk factor for cardiovascular disease and associated with increased morbidity and mortality in acromegaly. However there is little information on SDB in Japanese patients with acromegaly. We investigated the prevalence of SDB and association between the severity of SDB and various features and biomarkers in Japanese patients with acromegaly. Twenty-four Japanese patients with active acromegaly underwent overnight cardiorespiratory monitoring, hormonal assays and cephalometric measurements on X-ray. A high prevalence of SDB was detected in acromegaly (87.5\%). Log apnea-hypopnea index (AHI) correlated positively with soft palate length / body height (X-ray) ( $r=0.44, p=0.043)$, but not with log growth hormone levels and insulin-like growth factor type-1 standard deviation scores, size of pituitary adenoma, disease duration, body mass index, waist circumference, estimated visceral fat area, heel pad thickness / height, tongue thickness/ height, or oropharyngeal dimension/ height. In conclusion, our study demonstrated a high prevalence of SDB in Japanese patients with acromegaly, and its severity correlated with soft palate length. Based on the high incidence of SDB identified in the present study, we recommend that all patients with acromegaly are routinely screened for SDB for early diagnosis and treatment.
\end{abstract}

Key words: Acromegaly, Sleep-disordered breathing, Long soft palate

HABITUAL snoring and daytime hypersomnolence, i.e. sleep-disordered breathing (SDB), especially sleep apnea-hypopnea syndrome (SAS), are common features of acromegaly [1-4]. This serious complication represents an additional risk factor for cardiovascular disease and is associated with increased morbidity and mortality in acromegaly [5, 6]. Most patients with active acromegaly and SAS are reported to have the obstructive type of SAS (63-77\%) [6-8]. The pathophysiology of nocturnal airway obstruction is not yet clearly defined but is probably multifactorial. The persistently high levels of growth hormone (GH) and insulin-like growth factor-1 (IGF-1) in acromegaly can lead to anatomical changes, i.e. bone, cartilage, softtissue, and multiple organ enlargements [7, 8]. The

Submitted Aug. 1, 2011; Accepted Oct. 3, 2011 as EJ11-0171

Released online in J-STAGE as advance publication Oct. 12, 2011

Correspondence to: Ken Kishida, M.D., Ph.D., Department of Metabolism and Atherosclerosis, Graduate School of Medicine Osaka University, 2-2 B-5, Yamada-oka, Suita, Osaka, 565-0871, Japan. E-mail: kkishida@imed2.med.osaka-u.ac.jp presence of macroglossia, hypertrophy of the laryngeal mucosa, arytenoepiglottic and ventricular folds, and false vocal cords in active acromegaly results in narrowing of the oropharynx and/or larynx, thus facilitating partial or complete obstruction during sleep [7-12]. The reported prevalence of SAS in European adults with active acromegaly is relatively high (45-75\%) [13-16]. However, the prevalence and characteristics of SDB remain poorly defined in Japanese acromegalic patients [17]. In the present study, we investigated the prevalence of SDB in Japanese patients hospitalized with active acromegaly and elucidated the clinical variables associated with SDB evaluated by cardiorespiratory monitoring.
Abbreviations: AHI, apnea-hypopnea index; BMI, body mass index; CSA, central sleep apnea; GH, growth hormone; IGF-1, insulin-like growth factor-1; IMT, intima-media thickness; IRI, immunoreactive insulin; ODI, oxygen desaturation index; OSA, obstructive sleep apnea; SAS, sleep apnea-hypopnea syndrome; SDB, sleep-disordered breathing; VFA, visceral fat area; WC, waist circumference 


\section{Patients and Methods}

\section{Patients}

The study subjects were consecutive 24 Japanese patients diagnosed with active acromegaly who were hospitalized in the Department of Endocrinology and Metabolic Diseases, Osaka University Hospital, between January 2009 and December 2010. Hormonally active acromegaly was defined as a clinically apparent acromegaly with high levels of GH (normal, $\leq 2.7 \mathrm{ng} /$ $\mathrm{mL}$ ) and/or IGF-1 over sex- and age-adjusted normal range (upper limit of normal range) [18], and a lack of suppression of GH below $1 \mathrm{ng} / \mathrm{mL}$ after the oral administration of 75g-glucose [18]. The maximal size of the pituitary adenoma was measured by lateral, sagittal or coronal magnetic resonance image (MRI) (Signa HDxt 3T, version 16 GE Medical Systems, GE Healthcare, Tokyo, Japan). The adenomas were divided based on their size into microadenomas $(<10 \mathrm{~mm}$ in diameter, $\mathrm{n}=11)$ and macroadenomas $(\geq 10 \mathrm{~mm}$ in diameter, $n=13)$. For serum IGF-1 concentrations, results are expressed in SD (standard deviation) scores as recommended by the consensus guidelines of 2010 [19]. A SD score of less than 2.0 was considered normal in this study. In five subjects (males/females $=3 / 2$ ), serum prolactin at baseline was high levels over normal range ( $<15 \mathrm{ng} / \mathrm{mL}$ for men, $27 \mathrm{ng} / \mathrm{mL}$ for women), but serum prolactin increased more than twice in response to thyroid releasing hormone stimulating. All subjects were diagnosed with no hypopituitarism, by evaluating each pituitary hormone at baseline, and the response to luteinizing hormone releasing hormone and thyroid releasing hormone. Taken together, these findings indicated that the high level of circulating GH was caused by the GH-producing pituitary adenoma. In a male subject, free thyroxine at baseline was high levels over normal range and thyroid stimulating hormone levels were within the normal limit, but serum thyroid stimulating hormone increased less than twice in response to thyroid releasing hormone stimulation, possibly secreting both $\mathrm{GH}$ and thyroid stimulating hormone.

The duration of acromegaly was estimated from the occurrence of first symptoms or signs until diagnosis (12.7 \pm 1.7 years, range $2-30$ ). The numbers of patients with past history of coronary artery disease, cerebrovascular disease, congestive heart failure and malignant neoplasm were $0,0,3$ and 1 , respectively. The present study was approved by the ethics committee of Osaka University and a written informed con- sent was obtained from each participant. The registration number of the trial at the UMIN is 000002998 (The Endocrine-Metabolic Disease and Sleep Apnea Syndrome Study).

\section{Cardiorespiratory monitoring}

Before the treatment of acromegaly, the severity of SDB was assessed by all-night (9 PM to $6 \mathrm{AM}$ ) cardiorespiratory monitoring (Somté, Compumedics, Melbourne, Australia) that included nasal airflow using a pressure sensor, rib cage and abdominal wall movement using two stress-sensitive belts, body position with a body position sensor, arterial oxygen saturation $\left(\mathrm{SpO}_{2}\right)$ using a pulse oximeter, and electrocardiography $[20,21]$. The recorded signals were analyzed for the number of apneas and hypopneas [22]. The duration of sleep was estimated using the self-reported sleep time and the recorded data. The oxygen desaturation index (ODI), lowest $\mathrm{SpO}_{2}$, average $\mathrm{SpO}_{2}$, and time at desaturation $<90 \%$ in minutes of total bedtime for the entire night were measured. Apnea represented a decrease in the amplitude of airflow signal or thoracoabdominal motion to $<10 \%$ of the baseline for at least 10 seconds. Hypopnea was defined as a decrease in airflow or respiratory effort to $<70 \%$ of baseline for at least 10 seconds associated with $>4 \%$ desaturation but did not meet the criteria for an apnea. The apneahypopnea index (AHI) was defined as the total number of apneas/hypopneas per hour of sleep time [23]. Obstructive sleep apnea (OSA) represented absence of airflow for $\geq 10$ seconds but presence of thoracoabdominal movement (the amplitude of thoracic or abdominal wall motion remained $\geq 15 \%$ of baseline amplitude). Central sleep apnea (CSA) represented lack of airflow for $\geq 10$ seconds without thoracoabdominal movement $[22,23]$ (the amplitude of thoracic or abdominal wall motion decreased $<15 \%$ of baseline amplitude). Mixed apnea represented lack of airflow for $\geq 10$ seconds with an initial central component followed by obstructive component [22, 23]. All recordings were scored manually by an experienced polysomnographer [24]. SDB was diagnosed as $A H I \geq 5$. For analysis of autonomic dysfunction, the low frequency power (LF: 0.04 to 0.15 $\mathrm{Hz}$ ), which is influenced by sympathetic activity, and the high frequency power (HF: 0.15 to $0.40 \mathrm{~Hz}$ ), which is under vagal control and represents vagal heart activity, and the LF/HF ratio were computed. The LF/HF ratio is synchronous with respiratory frequency [25] and reflects sympathovagal modulation. Because the 
total frequency includes the sum of very low, low and high frequency power, the total frequency values were not included in this analysis.

\section{Anthropometry and laboratory measurements}

Height, weight and waist circumference (WC) were measured in standing position. WC at the umbilical level was measured with a non-stretchable tape in late expiration while standing (in $\mathrm{cm}$ ). Body mass index (BMI) was calculated [=weight $(\mathrm{kg}) /$ height $\left.(\mathrm{m})^{2}\right]$. Visceral fat area was estimated by bioelectrical impedance analysis (eVFA) [26]. The thickness of calcaneal heel pad was measured using lateral foot X-ray films, as reported previously [27]. Briefly, the thickness of the heel pad was measured perpendicularly from the most inferior aspect of the medial process of the calcaneus tuberosity to the top edge of the Perspex palate.

Venous blood samples were collected for measurements of blood glucose, immunoreactive insulin (IRI), low-density lipoprotein-cholesterol (LDL-C), triglyceride (TG), high-density lipoprotein-cholesterol (HDL-C), adrenocorticotropic hormone, cortisol, thyroid stimulating hormone, and free thyroxine, after awakening while the subject was in the supine position. Serum GH was determined by the chemiluminescent immunometric assay (normal range, GH; $\leq 6 \mathrm{ng} /$ $\mathrm{mL}$ ). Serum IGF-1 was determined by the immunoradiometric assay ("Daiichi” IGF-1 IRMA; FUJIFILM RI Pharma Co., Ltd., Tokyo, Japan). The homeostasis model assessment of insulin resistance (HOMA-IR) was calculated using the following formula (units): HOMA-IR $(\mathrm{mU} / \mathrm{L} \times \mathrm{mg} / \mathrm{dL})=($ fasting IRI $\times$ fasting glucose $) / 405$. Hypertension $(25 \%, n=6)$ was defined as systolic blood pressure $\geq 140 \mathrm{mmHg}$, and/or diastolic blood pressure $\geq 90 \mathrm{mmHg}$, or current treatment for hypertension (calcium channel antagonists/ angiotensin converting enzyme inhibitors/angiotensin receptor blockers/ $\beta$-blockers/diuretics; $n=1 / 3 / 4 / 3 / 0$ ). Diabetes mellitus $(37.5 \%, \mathrm{n}=9)$ was defined according to the World Health Organization criteria, or non-fasting plasma glucose concentration $\geq 200 \mathrm{mg} / \mathrm{dL}$, and/ or current treatment for diabetes mellitus (sulfonyl ureas/biguanides/alpha glucosidase inhibitors/Insulin; $\mathrm{n}=4 / 2 / 1 / 2)$. Dyslipidemia $(45 \%, \mathrm{n}=11)$ was defined as an LDL-C concentration of $>140 \mathrm{mg} / \mathrm{dL}$, TG concentration $\geq 150 \mathrm{mg} / \mathrm{dL}$, HDL-C concentration $<40 \mathrm{mg} /$ $\mathrm{dL}$, and/or treatment for dyslipidemia (statins/fibrates; $n=3 / 0$ ).
Measurement of carotid intima-media thickness (IMT)

The maximum carotid intima-media thickness (max IMT) and mean IMT of the common carotid artery were also measured in supine position (SSA-660A; Toshiba). The max IMT was measured on both the right and left sides in the observation-possible areas of the common carotid artery, bulbus and internal carotid artery, excluding the external carotid artery. The mean IMT represented the average of the values of the right and left common carotid arteries, but not the bulbus, determined at three points of measurements, as reported previously [20].

\section{Echocardiographic measurements}

Transthoracic M-mode, two-dimensional, pulse Doppler and color-Doppler echocardiographic measurements were performed from standard parasternal views in the resting state (SSA-660A; Toshiba, Tokyo), in the left lateral position, according to the recommendations of the American Society of Echocardiography [28]. Several parameters were measured, including the inter-ventricular septum thickness, posterior wall thickness, left atrial dimension, left ventricular internal end-diastolic diameter, left ventricular systolic diameter and left ventricular mass calculated by Devereux's Formula [29], modified with body surface area (left ventricular mass index).

\section{Cephalometric measurements}

Fig. 1 shows the cephalometric variables measured on the lateral head X-ray, as reported previously [8, 10, 12]. The plain radiographs were obtained under standard conditions during centric occlusion with the head fixed. All examinations were done with the patient awake in the supine position, with the head and neck extended in a neutral position. All measurements were made by the same examiner. The following cephalometric measurements were made; soft palate length and thickness, oropharyngeal dimension and tongue thickness.

\section{Statistical analysis}

Data are presented as mean \pm SEM. Relationships between two continuous variables were analyzed using scatter plots and Pearson's correlation coefficients. In all cases, two-tailed $p$ values were used, and $p$ values $<0.05$ were considered statistically significant. All analyses were performed with the JMP Statistical Discovery Software 8.0 (SAS Institute, Cary, NC). 


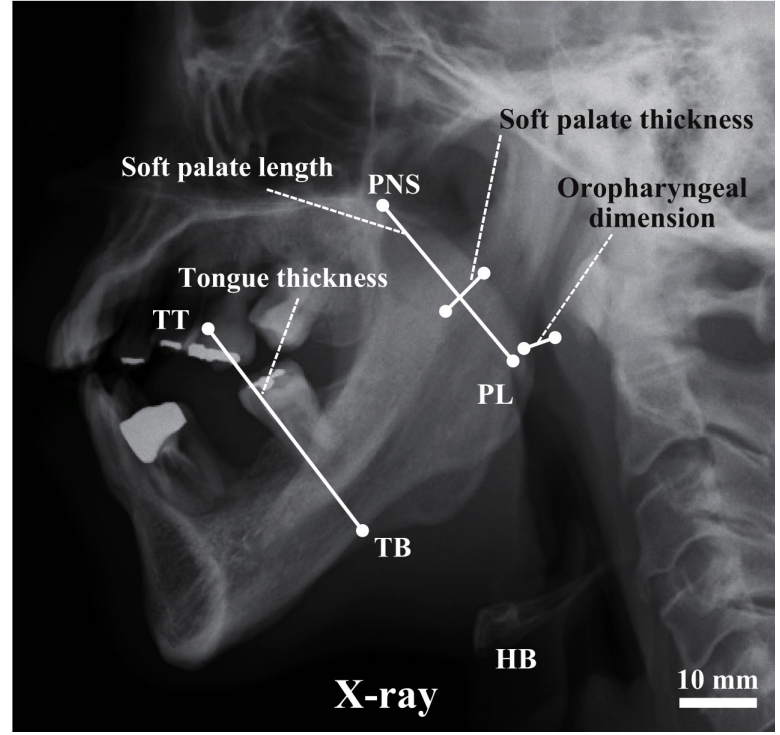

Fig. 1 Cephalometric examination

Lateral X-ray film showing the parameters measured in the present study.

PNS; posterior nasal spine, PL; lowest point of soft palate, TT; most anterior point of the top of the tongue, $\mathrm{HB}$; most anterior and inferior point of the hyoid bone, $\mathrm{TB}$; tonguebase. Oropharyngeal dimension; the narrowest dimension of the oropharyngeal dimension was measured, Tongue thickness; largest distance through TT and TB, Soft palate length; the line through PNS and PL, Soft palate thickness; the widest dimension of the soft palate thickness was measured.

\section{Results}

\section{Characteristics of acromegalic patients enrolled in the present study}

Table 1 summarizes the characteristics of acromegalic patients enrolled in this study. Of the 24 patients with acromegaly studied, 3 were considered to have no SAS. The prevalence of SDB was $87.5 \%(n=21 / 24)$, including $95.2 \%(n=20 / 21)$ with predominantly OSA. The average length of the soft palate was $43.2 \pm 1.7 \mathrm{~mm}$ (X-ray), and $83 \%$ of the patients $(n=20 / 24)$ had long soft palate (reference value: $29 \pm 3 \mathrm{~mm}$ [our unpublished data for Japanese patients with prolactinoma, $n=9]$ )

\section{Correlation analysis between AHI and measured parameters}

Data of AHI and GH showed skewed distribution, and therefore were log-transformed before analysis. Correlation analyses between log-AHI and clinic-biomarkers including cephalometric indices showed a positive correlation between log-AHI and soft pal-
Table 1 Baseline characteristics of acromegalic subjects.

\begin{tabular}{|c|c|}
\hline Age, years & $55.4 \pm 2.3(29-74)$ \\
\hline Gender (males/females) & $n=24(11 / 13)$ \\
\hline Body mass index, $\mathrm{kg} / \mathrm{m}^{2}$ & $24.9 \pm 0.6(20.1-32.4)$ \\
\hline Waist circumference, cm & $84.7 \pm 1.6(71-134)$ \\
\hline Estimated visceral fat area, $\mathrm{cm}^{2}$ & $84.6 \pm 7.9(34-161)$ \\
\hline HOMA-IR, units, $n=20$ & $1.9 \pm 0.2(0.5-3.6)$ \\
\hline Growth hormone, ng/mL & $13.0 \pm 2.9(1.3-52.6)$ \\
\hline Insulin-like growth factor-1, ng/mL & $850 \pm 75(262-1430)$ \\
\hline Insulin-like growth factor-1, SD score & $8.93 \pm 0.59$ \\
\hline Plasma adrenocorticotrophic hormone, pg/mL & $53.7 \pm 6.6(17-136)$ \\
\hline Serum cortisol, $\mu \mathrm{g} / \mathrm{dL}$ & $11.2 \pm 0.9(5.6-22.6)$ \\
\hline Thyroid stimulating hormone, $\mu \mathrm{U} / \mathrm{mL}$ & $0.8 \pm 0.1(0.22-2.51)$ \\
\hline Prolactin, ng/mL & $11.6 \pm 2.1(0.6-39.8)$ \\
\hline Free thyroxine, ng/dL & $1.2 \pm 0.1(0.8-2.4)$ \\
\hline Size of adenoma, mm & $13.4 \pm 1.7(5.1-34.0)$ \\
\hline Heel pad thickness, mm & $22.8 \pm 0.4(18.4-26.8)$ \\
\hline Mean intima-media thickness, mm & $0.83 \pm 0.05(0.5-1.27)$ \\
\hline Maximum intima-media thickness, mm & $1.27 \pm 0.11(0.6-2.7)$ \\
\hline Left ventricular ejection fraction, \% & $56.3 \pm 2.8(22.9-74.3)$ \\
\hline Left ventricular mass, $\mathrm{g} / \mathrm{m}^{3}$ & $121 \pm 11(74-245)$ \\
\hline \multicolumn{2}{|l|}{ Cephalometric findings } \\
\hline Soft palate length, mm (X-ray) & $43.2 \pm 1.5(26.9-56.9)$ \\
\hline Soft palate thickness, mm (X-ray) & $11.7 \pm 0.69(6.1-17.8)$ \\
\hline Oropharyngeal dimension, mm (X-ray) & $13.2 \pm 0.7(5.7-20.2)$ \\
\hline Tongue thickness, mm (X-ray) & $62.7 \pm 1.9(49.8-82.5)$ \\
\hline \multicolumn{2}{|l|}{ Cardiorespiratory monitoring } \\
\hline Apnea-hypopnea index, events/hour & $22.7 \pm 3.4(1.3-59.1)$ \\
\hline \multicolumn{2}{|l|}{ Severity of sleep-disordered breathing } \\
\hline No SDB $(\mathrm{AHI}<5)$ & $n=3$ \\
\hline Mild $(5 \leq$ AHI $<15)$ & $\mathrm{n}=7$ \\
\hline Moderate $(15 \leq \mathrm{AHI}<30)$ & $n=6$ \\
\hline Severe $(\mathrm{AHI} \geq 30)$ & $\mathrm{n}=8$ \\
\hline OSA-index, events/hour & $10.5 \pm 2.2(0-42.9)$ \\
\hline CSA-index, events/hour & $1.0 \pm 0.3(0-8.3)$ \\
\hline Hypopnea index, per hour & $8.5 \pm 1.2(0.7-20.5)$ \\
\hline Mixed type index, events/hour & $2.1 \pm 1.0(0-19.7)$ \\
\hline Average $\mathrm{SpO}_{2}, \%$ & $94.8 \pm 0.5(89.0-98.8)$ \\
\hline Lowest $\mathrm{SpO}_{2}, \%$ & $83.2 \pm 1.9(53.0-91.3)$ \\
\hline LF/HF ratio ${ }^{2}$ & $1.2 \pm 0.4(0.6-2.9)$ \\
\hline
\end{tabular}

Data are mean \pm SEM (range). Numbers (n) of subjects analyzed are shown in parenthesis. HOMA-IR; homeostasis model assessment-insulin resistance, SD (standard deviation).

ate length (X-ray) (data not shown, $r=0.45, p=0.041$ ). As soft palate length is influenced potentially by body constitution, it was divided by body height. Log-AHI correlated positively with soft palate length / body height (X-ray) (Table 2 and Fig. 2, $r=0.44, p=0.043$ ). However, there was no significant correlation between AHI and age, BMI, WC (all, male, female), eVFA (all, male, female), log-GH and IGF-1 SD score, size of adenoma, duration of acromegaly, heal pad thickness, mean and maximum IMT (all, male, female), left ventricular 
Table 2 Correlation between AHI and various clinico-biochemical parameters

\begin{tabular}{|c|c|c|c|c|c|c|}
\hline \multirow{2}{*}{ Log AHI } & \multicolumn{2}{|c|}{ Univariate (all) } & \multicolumn{2}{|c|}{ Univariate (male) } & \multicolumn{2}{|c|}{ Univariate (female) } \\
\hline & $r$ & $p$ value* & $r$ & $p$ value* & $r$ & $p$ value* \\
\hline Age & 0.31 & 0.13 & - & - & - & - \\
\hline Gender (male) & - & 0.76 & - & - & - & - \\
\hline Body mass index & 0.03 & 0.90 & - & - & - & - \\
\hline Waist circumference & 0.04 & 0.86 & 0.15 & 0.76 & 0.10 & 0.73 \\
\hline Estimated visceral fat area & 0.15 & 0.51 & 0.02 & 0.97 & 0.36 & 0.28 \\
\hline Log growth hormone & 0.21 & 0.32 & 0.32 & 0.21 & 0.32 & 0.32 \\
\hline Insulin-like growth factor-1 SD score & 0.04 & 0.87 & - & - & - & - \\
\hline Size of adenoma & 0.21 & 0.34 & - & - & - & - \\
\hline Duration of acromegaly & 0.14 & 0.50 & - & - & - & - \\
\hline Heal pad thickness & 0.25 & 0.24 & - & - & - & - \\
\hline Heal pad thickness / height & 0.16 & 0.47 & - & - & - & - \\
\hline Mean intima-media thickness & 0.36 & 0.11 & 0.23 & 0.33 & 0.41 & 0.24 \\
\hline Maximum intima-media thickness & 0.17 & 0.47 & 0.28 & 0.43 & 0.02 & 0.95 \\
\hline Left ventricular ejection fraction & 0.21 & 0.36 & - & - & - & - \\
\hline Left ventricular mass index & 0.24 & 0.31 & - & - & - & - \\
\hline Soft palate length / height (X-ray) & 0.44 & $<0.05$ & - & - & - & - \\
\hline Soft palate thickness / height (X-ray) & 0.17 & 0.48 & - & - & - & - \\
\hline Oropharyngeal dimension / height (X-ray) & 0.16 & 0.48 & - & - & - & - \\
\hline Tongue thickness / height (X-ray) & 0.21 & 0.37 & - & - & - & - \\
\hline
\end{tabular}

* by Pearson's correlation analysis

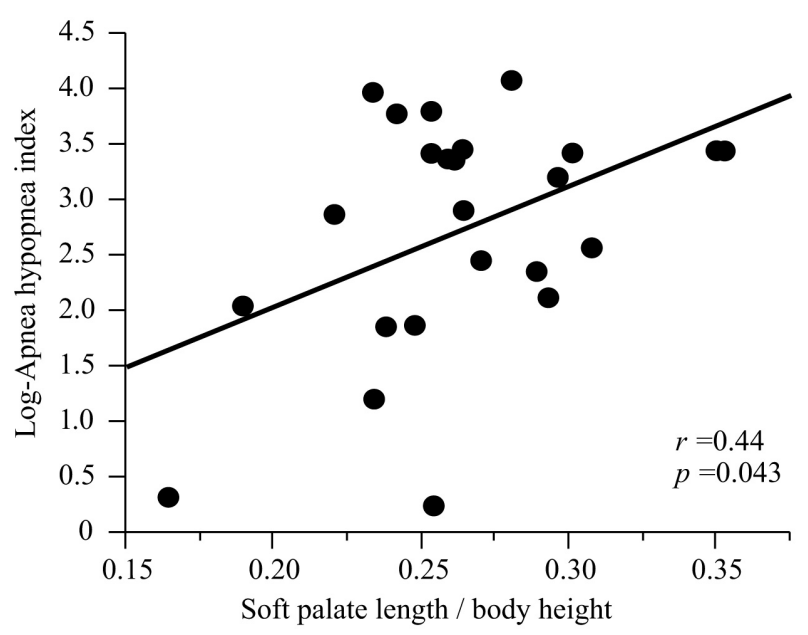

Fig. 2 Correlation between log AHI and soft palate length / height (X-ray)

Pearson's correlation analysis was used to examine the relationship between log apnea hypopnea index (AHI) and soft palate length / height (X-ray).

ejection fraction, left ventricular mass index, soft palate thickness / body height, oropharyngeal dimension / body height, tongue thickness / body height (Table 2).

\section{Discussion}

The major findings of the present study were: 1) high prevalence of SDB in Japanese patients with acromegaly (87.5\%), consistent with previous studies in Europeans [13-16], 2) the severity of SDB in these patients correlated with a large soft palate, as previous report showed that soft palate length was significantly larger in OSA patients compared to controls [30]. Previous report in Japanese acromegalic patients showed that all oximetric parameters with a bedside oximeter showed worsen results in SDB group than in non-SDB group [17], but the present study investigated the relationship between the severity of SDB (i.e. AHI) with cardiorespiratory monitoring and various parameters in Japanese acromegalic patients, which to our knowledge is the first such report. Previous studies in European acromegalic patients showed that SDB correlates with high levels of GH and IGF-1 [3, 13, 15], aging [10, 12, 14, 15], male gender, BMI [14], WC [14], neck circumference [15] and tongue size [30, 31]. Although we reported previously that AHI correlated with BMI and WC in diabetic patients [20,21], the present study found no correlation between $\mathrm{AHI}$ and BMI and WC in acromegalic patients (Table 2), probably because acromegaly is often a disease with little fat but organ hypertrophy, different from diabetes. The present study found that AHI correlated significantly with soft palate length / body height only (Table 2); supporting the view that SDB in these patients corre- 
lates with the collapse of a large and floppy soft palate. However, since this is a cross-sectional study, it is difficult to establish cause-effect relationship. In the present study, soft palate length (X-ray) and soft palate length/body height (X-ray) correlated significantly with duration of acromegaly $(r=0.57, p<0.01 ; r=0.55$, $p<0.01$; respectively, data not shown), but did not with circulating GH and IGF levels ( $p=0.75, p=0.97 ; p=0.70$, $p=0.87$; respectively, data not shown). These findings indicate that the presence of chronically high GH and IGF-1 levels is more important than absolute values of GH and IGF-1 in blood at diagnosis for the association of SDB with longer soft palate, similar to the relation with the heal pad thickness in acromegaly $[7,8]$.

SDB is classified into OSA and CSA. Grunstein et al. reported that patients with CSA have significantly higher GH and IGF-1 levels than patients with OSA [4]. A postulated but not documented impairment of the somatostatin pathway in acromegaly (indeed an increased somatostatinergic tone, reactive to the high GH levels, has also been postulated) might be also responsible for the chemoreceptor hypersensitivity with attendant hyperventilatory responses to chemical stimuli [4]. Only one of our patients with acromegaly had predominantly CSA. Further studies of a larger population sample of acromegalic patients are needed to clarify this issue.

Several studies have indicated that surgery or medical therapy for acromegaly reversed SDB. Resection of the pituitary adenoma is reported to result in significant improvement or disappearance of SDB [32-34], although such treatment is also reported to have no such effect with persistence of SDB [35]. The latter is probably related to the irreversible changes in the craniofacial region and upper respiratory tract [36]. Treatment with octreotide (somatostatin analogue) is reported to reduce the severity of SDB, although SDB can persist after normalization of hormonal levels [31, 37-40]. Thus, the exact effect of treatment of acromegaly on SDB remains controversial. In the present study, after hospitalization, 22 patients were treated by transsphenoidal resection of pituitary gland adenoma, while two patients were treated with octreotide. The present study did not investigate the comparison between SDB of pre- and post-treatment for acromegaly. Further prospective studies are required to determine the short- and long-term effects of treatment of acromegaly on SDB and cephalometric examination in Japanese patients with acromegaly.
The prevalence of hypertension, diabetes and dyslipidemia in our acromegalic patients was 25\%, 37.5\%, and $45 \%$, respectively. Both SDB and acromegaly share common symptoms and prognostic features: high cardiovascular and respiratory mortality rates, high incidence of hypertension, and glucose-lipid dysmetabolism. Early diagnosis of SDB in acromegalic patients may identify a group at higher cardiovascular risk, in whom complications of acromegaly may be more pronounced. Based on the high incidence of SDB demonstrated in the present study, we advise that all patients with acromegaly should be routinely screened for SDB for early treatment and potential prevention of future cardiovascular events.

We used a conventional overnight cardiorespiratory monitoring to assess SDB without electro encephalogram. The duration of sleep by self-reported sleep time and the recorded data might overestimate real sleeping time based on electro encephalogram and thus underestimate AHI. Although polysomnography is required to accurately assess sleep duration and structure and is currently considered the 'gold standard' method to diagnose SDB including OSA whether attended or not, time spent on analysis and interpretation of the data obtained, by technical and medical staff means it may not be the most cost-effective or convenient method of assessing sleep disordered breathing in the large number of patients who present with acute coronary syndromes and require secondary prevention of adverse outcomes in this urgent setting.

In conclusion, we found high prevalence of SDB in Japanese patients with acromegaly, in agreement with the results of previous studies from other countries [13-16]. Early diagnosis of SDB in acromegaly is emphasized for preventing cardiovascular events, since it is a treatable disorder.

\section{Acknowledgment}

We are grateful to Dr. Tetsuhiro Kitamura and Dr. Kohei Okita for patients' enrollment, Dr Michio Otuki for helpful discussion, and Mr. Masato Tanaka for help with apnomonitor scoring and analysis. This work was supported in part by a Grant-in-Aid for Scientific Research No. (C) No. 21591177 (to K.K.).

\section{Appendix}

The authors declare no conflict of interest. 


\section{References}

1. Scacchi M, Cavagnini F (2006) Acromegaly. Pituitary 9: 297-303.

2. Chanson P, Salenave S (2008) Acromegaly. Orphanet $J$ Rare Dis 3: 17.

3. Perks WH, Horrocks PM, Cooper RA, Bradbury S, Allen A, Baldock N, Prowse K, van’t Hoff W (1980) Sleep apnoea in acromegaly. Br Med J 280: 894-897.

4. Grunstein RR, Ho KY, Sullivan CE (1991) Sleep apnea in acromegaly. Ann Intern Med 115: 527-532.

5. Giustina A, Casanueva FF, Cavagnini F, Chanson P, Clemmons D, Frohman LA, Gaillard R, Ho K, Jaquet P, Kleinberg DL, Lamberts SW, Lombardi G, Sheppard M, Strasburger CJ, Vance ML, Wass JA, Melmed S; Pituitary Society and the European Neuroendocrine Association (2003) Diagnosis and treatment of acromegaly complications. J Endocrinol Invest 26: $1242-$ 1247.

6. Colao A, Ferone D, Marzullo P, Lombardi G (2004) Systemic complications of acromegaly: epidemiology, pathogenesis, and management. Endocr Rev 25: 102152.

7. Cadieux RJ, Kales A, Santen RJ, Bixler EO, Gordon R (1982) Endoscopic findings in sleep apnea associated with acromegaly. J Clin Endocrinol Metab 55: 18-22.

8. Hochban W, Ehlenz K, Conradt R, Brandenburg U (1999) Obstructive sleep apnoea in acromegaly: the role of craniofacial changes. Eur Respir J 14: 196-202.

9. Mickelson SA, Rosenthal LD, Rock JP, Senior BA, Friduss ME (1994) Obstructive sleep apnea syndrome and acromegaly. Otolaryngol Head Neck Surg 111: 25-30.

10. Dostalova S, Sonka K, Smahel Z, Weiss V, Marek J, Horinek D (2001) Craniofacial abnormalities and their relevance for sleep apnoea syndrome aetiopathogenesis in acromegaly. Eur J Endocrinol 144: 491-497.

11. Rodrigues MP, Naves LA, Casulari LA, Silva CM, Paula WD, Cabral MT, Araujo RR, Viegas CA (2008) Craniofacial abnormalities, obesity, and hormonal alterations have similar effects in magnitude on the development of nocturnal hypoxemia in patients with acromegaly. J Endocrinol Invest 31: 1052-1057.

12. van Haute FR, Taboada GF, Corrêa LL, Lima GA, Fontes R, Riello AP, Dominici M, Gadelha MR (2008) Prevalence of sleep apnea and metabolic abnormalities in patients with acromegaly and analysis of cephalometric parameters by magnetic resonance imaging. Eur $J$ Endocrinol 158: 459-465.

13. Hart TB, Radow SK, Blackard WG, Tucker HS, Cooper KR (1985) Sleep apnea in active acromegaly. Arch Intern Med 145: 865-866.

14. Rosenow F, Reuter S, Deuss U, Szelies B, Hilgers RD, Winkelmann W, Heiss WD (1996) Sleep apnoea in treated acromegaly: relative frequency and predispos- ing factors. Clin Endocrinol (Oxf) 45: 563-569.

15. Weiss V, Sonka K, Pretl M, Dostálová S, Klozar J, Rambousek P, Marek J, Haas T (2000) Prevalence of the sleep apnea syndrome in acromegaly population. $J$ Endocrinol Invest 23: 515-519.

16. Davi’ MV, Dalle Carbonare L, Giustina A, Ferrari M, Frigo A, Lo Cascio V, Francia G (2008) Sleep apnoea syndrome is highly prevalent in acromegaly and only partially reversible after biochemical control of the disease. Eur J Endocrinol 159: 533-540.

17. Saeki N, Isono S, Nishino T, Iuchi T, Yamaura A (1999) Sleep-disordered breathing in acromegalics--relation of hormonal levels and quantitative sleep study by means of bedside oximeter. Endocr J 46: 585-590.

18. Anonymous (The Japan Endocrine Society). Diagnosis and treatment of acromegaly and pituitary gigantism: consensus guidelines (in Japanese). http://square.umin. ac.jp/endocrine/tebiki/001/001001.pdf

19. Giustina A, Chanson P, Bronstein MD, Klibanski A, Lamberts S, Casanueva FF, Trainer P, Ghigo E, Ho K. Melmed S (2010) A consensus on criteria for cure of acromegaly. J Clin Endocrinol Metab 95: 3141-3148.

20. Kashine S, Kishida K, Funahashi T, Nakagawa Y, Otuki M, Okita K, Iwahashi H, Kihara S, Nakamura T, Matsuzawa Y, Shimomura I (2010) Characteristics of sleep-disordered breathing in Japanese patients with type 2 diabetes mellitus. Metabolism 59: 690-696.

21. Kashine S, Kishida K, Funahashi T, Yasuda T, Okita K, Matsuzawa Y, Shimomura I (2011) Selective contribution of waist circumference reduction on the improvement of sleep-disordered breathing in patients hospitalized with type 2 diabetes mellitus. Intern Med 50:1895-1903.

22. Kushida CA, Littner MR, Morgenthaler T, Alessi CA, Bailey D, Coleman J Jr, Friedman L, Hirshkowitz M, Kapen S, Kramer M, Lee-Chiong T, Loube DL, Owens J, Pancer JP, Wise M (2005) Practice parameters for the indications for polysomnography and related procedures: an update for 2005. Sleep 28: 499-521.

23. Anonymous (1999) Sleep-Related Breathing Disorders in Adults: recommendations for syndrome definition and measurement techniques in clinical research. The Report of an American Academy of Sleep Medicine Task Force. Sleep 22: 667-689.

24. Collop NA, Anderson WM, Boehlecke B, Claman D, Goldberg R, Gottlieb DJ, Hudgel D, Sateia M, Schwab $\mathrm{R}$; Portable Monitoring Task Force of the American Academy of Sleep Medicine (2007) Clinical guidelines for the use of unattended portable monitors in the diagnosis of obstructive sleep apnea in adult patients. Portable Monitoring Task Force of the American Academy of Sleep Medicine. J Clin Sleep Med 3: 737747. 
25. Anonymous (1996) Task Force of the European Society of Cardiology the North American Society of Pacing and Electrophysiology. Heart rate variability: standards of measurement, physiological interpretation, and clinical use. Circulation 93: 1043-1065.

26. Ryo M, Maeda K, Onda T, Katashima M, Okumiya A, Nishida M, Yamaguchi T, Funahashi T, Matsuzawa Y, Nakamura T, Shimomura I (2005) A new simple method for the measurement of visceral fat accumulation by bioelectrical impedance. Diabetes Care 28: 451-453.

27. MacSweeney JE, Baxter MA, Joplin GF (1990) Heel pad thickness is an insensitive index of biochemical remission in acromegaly. Clin Radiol 42: 348-350.

28. Sahn DJ, DeMaria A, Kisslo J, Weyman A (1978) Recommendations regarding quantitation in M-mode echocardiography: results of a survey of echocardiographic measurements. Circulation 58: 1072-1083.

29. Devereux RB, Reichek N (1977) Echocardiographic determination of left ventricular mass in man. Anatomic validation of the method. Circulation 55: 613-618.

30. Shigeta Y, Ogawa T, Tomoko I, Clark GT, Enciso R (2010) Soft palate length and upper airway relationship in OSA and non-OSA subjects. Sleep Breath 14: 353358.

31. Isono S, Saeki N, Tanaka A, Nishino T (1999) Collapsibility of passive pharynx in patients with acromegaly. Am J Respir Crit Care Med 160: 64-68.

32. Ip MS, Tan KC, Peh WC, Lam KS (2001) Effect of Sandostatin LAR on sleep apnoea in acromegaly: correlation with computerized tomographic cephalometry and hormonal activity. Clin Endocrinol (Oxf) 55: 477483.

33. Main G, Borsey DQ, Newton RW (1988) Successful reversal of sleep apnoea syndrome following treatment for acromegaly, confirmed by polygraphic studies. Postgrad Med J 64: 945-946.

34. Sze L, Schmid C, Bloch KE, Bernays R, Brändle M (2007) Effect of transsphenoidal surgery on sleep apnoea in acromegaly. Eur J Endocrinol 156: 321-329.

35. Piper JG, Dirks BA, Traynelis VC, VanGilder JC (1995) Perioperative management and surgical outcome of the acromegalic patient with sleep apnea. Neurosurgery 36: 70-74.

36. Pelttari L, Polo O, Rauhala E, Vuoriluoto J, Aitasalo K, Hyyppä MT, Kronholm E, Irjala K, Viikari J (1995) Nocturnal breathing abnormalities in acromegaly after adenomectomy. Clin Endocrinol (Oxf) 43: 175-182.

37. Tolis G, Angelopoulos NG, Katounda E, Rombopoulos G, Kaltzidou V, Kaltsas D, Protonotariou A, Lytras A (2006) Medical treatment of acromegaly: comorbidities and their reversibility by somatostatin analogs. Neuroendocrinology 83: 249-257.

38. Grunstein RR, Ho KK, Sullivan CE (1994) Effect of octreotide, a somatostatin analog, on sleep apnea in patients with acromegaly. Ann Intern Med 121: 478483.

39. Leibowitz G, Shapiro MS, Salameh M, Glaser B (1994) Improvement of sleep apnoea due to acromegaly during short-term treatment with octreotide. J Intern Med 236: 231-235.

40. Herrmann BL, Wessendorf TE, Ajaj W, Kahlke S, Teschler H, Mann K (2004) Effects of octreotide on sleep apnoea and tongue volume (magnetic resonance imaging) in patients with acromegaly. Eur J Endocrinol 151: 309-315. 